\title{
Exposure to occupational hazards for pregnancy and sick leave in pregnant workers: a cross-sectional study
}

\author{
Jean-Bernard Henrotin ${ }^{1 *}$, Monique Vaissière ${ }^{2}$, Maryline Etaix ${ }^{3}$, Mathieu Dziurla' ${ }^{1}$ Stéphane Malard ${ }^{4}$ \\ and Dominique Lafon ${ }^{5}$
}

\begin{abstract}
Background: This study aimed to investigate the association between exposure to occupational hazards for pregnancy and sick leave (SL) in pregnant workers.

Methods: A cross-sectional study was performed in French occupational health services in 2014. Occupational hazards for pregnancy were assessed by occupational health physicians (OHPs). After delivery and at the time of returning to work, 1,495 eligible workers were interviewed by OHPs. Information on SL was self-reported. Risk ratios (RRs) were calculated from multivariable analyses based on a generalized linear model with a Bernoulli distribution and a log link adjusted for selected confounders for binary outcomes or zero-inflated negative binomial regression for count outcomes.

Results: Among recruited workers, 74.9\% presented "at least one SL" during pregnancy. After adjustment, the cumulative index of occupational hazards $(0,1-2,3-4, \geq 5$ risks) for pregnancy was significantly associated with "at least one SL" during pregnancy in a dose-response relationship. This gradient was also observed with "early SL" ( $<15$ week gestation): from 1 to 2 risks, $R R=1.48$ (95\% confidence intervals (Cls): 0.92-2.38); from 3 to 4 risks, $R R=2.03$ ( $95 \%$ Cl: 1.25-3.30); equal to or higher than five risks, $\mathrm{RR}=2.90$ (95\% Cl: 1.89-4.44); with "duration of absence" (adjusted mean): from 1 to 2 risks, $m=38.6$ days; from 3 to 4 risks, $m=46.8$ days; equal to or higher than five risks, $m=53.8$ days. We also found that deprivation, pregnancy at risk, assisted reproductive therapy, work-family conflicts, home-work commuting felt as difficult and young age are associated with a higher risk of SL.
\end{abstract}

Conclusions: Our results support the assertion that pregnant workers exposed to occupational hazards for pregnancy without medical complications are also at risk of taking SL during pregnancy. More prevention in the workplace for pregnant workers exposed to occupational hazards could reduce SL.

\section{Background}

In several European countries concerning pregnant workers, it exists in the workplace protective legislation where employers should adjust work conditions according to the needs of pregnancy [1-3]. Despite this, sick leave (SL) levels among pregnant workers have increased over the last few decades and remain extremely high today without clear explanations [4-12]. In France, pregnant workers may take legal prenatal leaves (from 6 to

\footnotetext{
* Correspondence: jeanbernardhenrotin@wanadoo.fr

'Department of Occupational Epidemiology, National Research and

Safety Institute, 1 rue du Morvan, CS 60027, Vandoeuvre-les-Nancy 54519

Cedex, France

Full list of author information is available at the end of the article
}

8 weeks) before the date of delivery or "pathological leave" (2 weeks) in case of medical complications during pregnancy. Outside of these periods, a pregnant worker may take ordinary SL but will receive $50 \%$ of her salary. Several factors have been reported in the literature to be associated with SL during pregnancy: occupational groups $[4,8,9,12-14]$, assisted reproductive therapy (ART) [15], body mass index [14, 15], social benefits [16, 17], attitudes regarding SL in the workplace $[6,10,16]$, and young women [8]. Also, some occupational exposures have also been associated with SL during pregnancy $[4,7,13,15,16,18,19]$.

However, particularly in pregnant workers, studies remain scarce and occupational explanations of the high 
rate of SL need to be confirmed. The studies are rather small in size [7, 13], limited to certain occupations [7], without accurate exposure measurements [4, 7] and often limited or no adjustment for potential confounders $[4,7,13]$. Almost studies from the available literature have been carried out in north European countries [4, 7, $15,17,20-22]$ and to our knowledge, none in France. It is important to note that several studies report that job adjustment is associated with reduced SL during pregnancy $[23,24]$. Therefore, in order to propose preventive measures in the workplace and reduce the risk of SL, it is necessary to deepen relationship between occupational exposures and SL during pregnancy.

We hypothesized that pregnant workers without medical complications during pregnancy exposed to occupational hazards for pregnancy are at risk of taking SL during pregnancy. The aim of this study was to investigate the association between exposure to occupational hazards for pregnancy and SL in pregnant workers.

\section{Methods}

\section{Design and study population}

A cross-sectional study was performed from January 1, 2014 to December 31, 2014 in the occupational health services of the Languedoc-Roussillon region and in the town of Roanne in France. Eighty-three occupational health physicians (OHP) participated in the recruitment of workers.

According to French labor law, each woman having worked during pregnancy must benefit from a medical visit with an OHP after delivery and at the time of returning to work. This is a compulsory visit for employers and employees. Also, at the first postnatal visit, all women (no selection method) were invited to participate in the study by the OHP. The inclusion criteria were that they: (i) must have worked for an employer during their last pregnancy (our study did not include workers without employment contract (such as selfemployed, craftsman, farmer, company head...) because these workers were not followed by French occupational health services); (ii) to be older than 18 years of age (legal majority in France) (iii) must have had a postnatal visit with an OHP in the year after delivery; or (iv) within three years after delivery if they had full-time parental leave; and (v) be sufficiently fluent in French to participate in the interview. Before the medical visit, the OHPs asked eligible workers to fill-in a selfadministered questionnaire to obtain sociodemographic information; during the visit, a second occupational questionnaire was administered face-to-face by the OHP. The computerized medical record system in each occupational health service was declared to the French National Commission for Data Protection. All the volunteer participants gave their informed consent to be enrolled and data were collected anonymously. Because we used anonymised data from routine medical visits, in 2013 according to French law, ethics approval was not required.

\section{Outcomes of interest}

Information on SL during pregnancy was obtained from workers with the following questions by taking account of leaves for legal reasons and sickness: (i) for the first and second trimester of the pregnancy ("did you have one SL before a pathological or legal leave (regardless of the cause and duration)?, yes/no); (ii) on the duration ("what was the total duration of your SL, before a pathological or legal leave?, in days during pregnancy); (iii) "did you take a SL without returning to work before a pathological or legal leave ?, yes/no ? If yes, at what time of your pregnancy did you stop working completely? in which week of gestation (WG)". In this study, we defined each trimester in the following way: first trimester when < 15 WG; second trimester from 15 WG to 28 WG. Early SL was defined as leaving job before 15 WG.

\section{Exposure of interest}

The exposure assessment of potential hazards for pregnancy was conducted by OHPs based on knowledge of workstations in early pregnancy. Seventeen potential hazards were selected [3]: biological hazards (working with very young children, sick persons, animals); chemical hazards; night work (between 9:00.p.m and 5:00 a.m.); physical hazards (standing $>1 \mathrm{~h}$ a day, stair climbing (several times a day), forward bending $\geq 1 \mathrm{~h}$ a day, difficult postures (upper and/or lower limbs), heavy lifting $>5 \mathrm{~kg}$, repetitive tasks, vibration (driving), temperature $\left(>30{ }^{\circ} \mathrm{C},<10^{\circ} \mathrm{C}\right)$, noise $>80 \mathrm{~dB}$, work on industrial machines); ionizing radiation and electromagnetic fields. The responses were based on a 4-point Likert scale ranging from 1: no; 2 : very rarely (a few per month); 3: sometimes (a few times a week); 4: frequently (a few times a day or more). Then, all these variables were transformed into binary variables and were coded as either 0 (to indicate the reference category) or 1 (to indicate the category at risk). For all the variables, the category at risk was the "frequently" category (level 4) except for three variables: ionizing radiation (level from 2 to 4); night work (at least one night); Electromagnetic fields (level from 3 to 4). A cumulative index of occupational hazards for pregnancy in four classes $(0,1-2,2-4$, $\geq 5$ risks) was built using these seventeen occupational variables.

\section{Potential confounders}

The choice of potential confounders was based on the literature data (age, deprivation, occupational data, number of children, assisted reproductive therapy (ART), and 
pregnancy at risk) except for smoking, alcohol consumption, and body mass index. We have considered that socioeconomic deprivation was a proxy measure for these last three variables because very positively correlated to them [25]. Socioeconomic deprivation was assessed using the Evaluation of Deprivation and Inequalities in Health Examination (EPICES) individual scale [25]. This is a reliable proxy in workplace settings for populationbased measures of deprivation which is strongly correlated with the Townsend and Carstairs indices [25]. Workers with an EPICES score equal to or higher than 30 were classified as being deprived. Occupational skill level was classified according to the French standard classification of occupations (version 2003) from the French National Institute of Statistics [26]. The occupations were classified into four skill levels: managers/supervisors, intermediate occupations, employees, and manual workers. Women were asked if they had been followed-up for "pregnancy at risk of medical complications" (yes/no) and whether they had had assisted reproductive therapy (yes/no). Other explored factors were maternal age at delivery, company size at four levels $(<10,10-49,50-199, \geq 200$ workers), type of contract (non-fixed term, fixed term), home-work commuting (duration, mode), working time (full-time, part-time), and job duration $(<2, \geq 2$ years).

Several factors, no used in literature like confounders until now, related to concept "work-family conflict" were also used $[27,28]$. This concept focuses on the difficulties that employees have in balancing their work and family responsibilities which could increase fatigue during pregnancy and the occurrence of SL $[27,28]$. In our study, several predictors of work-family conflict were used as follows. An index of cumulated workfamily conflict risks in four classes $(0,1,2, \geq 3$ risks) was built using five dichotomous variables: preschoolage children at home (yes/no), home-work commuting $>50 \mathrm{~min} / \mathrm{d}$ (yes/no), duration of working hours $>8 \mathrm{~h} / \mathrm{d}$ (yes/no), irregular working hours (yes/no), and absence of two consecutive rest days in a week (yes/no).

\section{Statistical analyses}

In bivariate analyses, chi-square tests were used to compare binary variables. Also for continuous variables, the Kolmogorov-Smirnov test was used to evaluate the normal distribution. A Student's $t$-test was used to analyze the normally distributed quantitative values, and the Mann-Whitney $U$ test or the Kruskal-Wallis test was used to analyze the non-normally distributed ones. In multivariate analyses for binary outcomes, adjusted relative risks ( $\mathrm{RRa}$ ) with $95 \%$ confidence intervals $(\mathrm{CIs})$ were calculated based on a generalized linear model with a Bernoulli distribution and a log link adjusted for selected confounders [29]. A stepwise forward procedure was conducted to identify the variables having a significant association with the outcome. For "at least one sick leave" variable, we have conducted analyses separately for each trimester of pregnancy because the impact of the factor may be different according to the pregnancy period. To compare the results between trimesters, we have presented the significant variables from final models of the stepwise forward procedure but also the non-significant variables adjusted for these significant variables. Also, we tested interaction terms between several variables. Notably, to answer our hypothesis, analyses between "number of occupational risks for pregnancy" and "pregnancy at risk" were carried out separately when a positive interaction was identified between these two variables. For count outcome, zeroinflated negative binomial regression (ZINB) was carried out to take into account over-dispersion and/or excess of the zero value in data [30]. For this outcome the purpose of the analysis was exploratory, we have presented the results without a selection procedure of the variables. A two-sided p-value of less than 0.05 was considered statistically significant in our study. Statistical power was estimated on the basis of a binomial test with unequal group sizes (ratio 1/4). In this case to detect an effect size of $R R=2$ with $80 \%$ power at a significance level of 0.05 and a control-group proportion at $5 \%, 1,245$ pregnant workers were required. As the responses were relatively complete, analyses excluded missing data. All the statistical analyses were performed using STATA statistical software, version 14.0 (Stata Corp, College Station, Texas, USA).

\section{Results}

During the study time period, the number of workers recruited was 1,581 (Fig. 1). The number of cases excluded was 64 workers (non-valid files). Very few women refused to participate, with only 22 cases not included in the study. Thus, our final sample was composed of 1,495 workers. The mean of the proportion of missing data was $1.8 \%$ per variable with two variables above $5 \%$ : deprivation (6.2\%) and job duration (6.5\%).

Table 1 presents a description of the pregnant workers according to the occurrence of "at least one SL" before a pathological or legal prenatal leaves (Table 1). The proportion of "at least one SL" was 74.9\%. SLs were less frequent in the managers/supervisors group and in small companies ( $<50$ workers). Workers with "non-fixed contracts", "pregnancy at risk" or ART had an increased proportion of SL. Note that the age mean was not different between the two groups.

Figure 2 displays the frequencies of the potential occupational hazards for pregnancy in worker groups with and without SL (Fig. 2). We observed that exposures to physical hazards (standing $>1 \mathrm{~h}$, heavy lifting, forward 


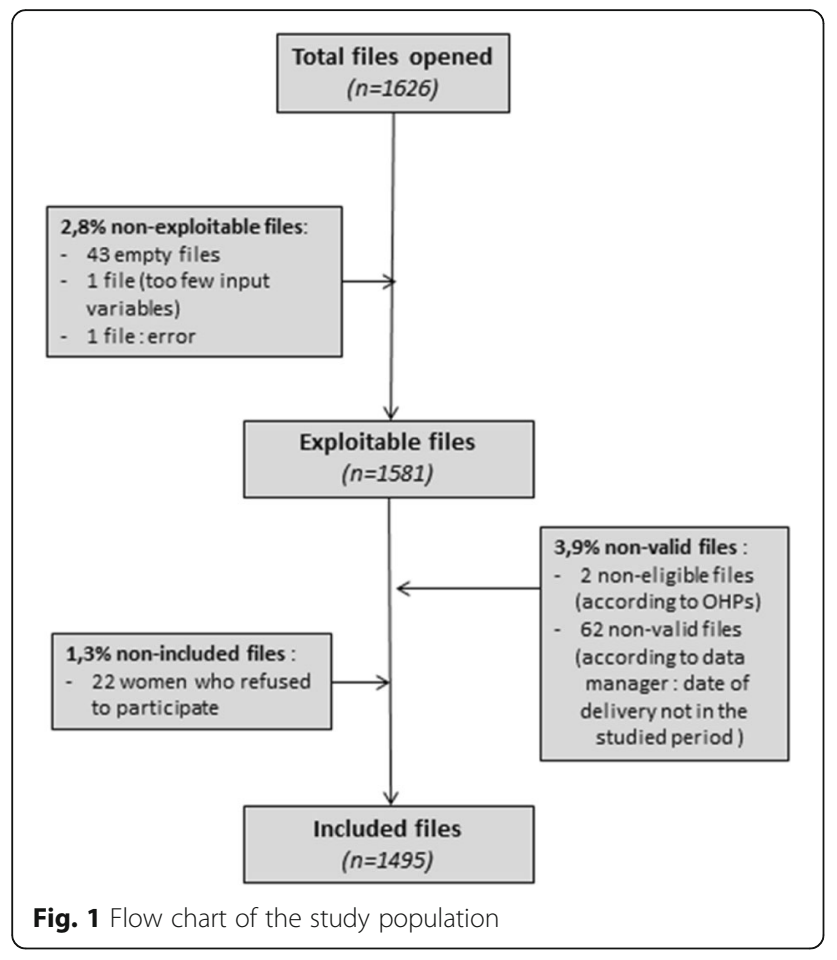

bending, stair climbing, and difficult postures) and, although less frequent, biological hazards, exposure to chemical products and night work were significantly associated with SL.

Table 2 shows adjusted relative risks ( $\mathrm{RRa}$ ) with 95\% confidence intervals for "at least one SL" from 1st trimester to 3rd trimester of gestation (Table 2). In the first trimester, the "number of occupational hazards", deprivation, "pregnancy at risk" and ART were associated with higher RRa of SL compared to the reference group. Note that the RRa of the "number of occupational hazards" increased in a dose-dependent way. In the two other trimesters the results were presented separately for pregnant workers without and with "pregnancy at risk" because of statistical interaction between "pregnancy at risk" and the "number of occupational hazards". Like ART variable was very correlated to "pregnancy at risk"(data not shown), this variable was not presented to second and third trimester. The gradient with "number of occupational hazards" was also observed for all the strates except for 3rd trimester in the strate with "pregnancy at risk" and the strength of effect was strongest to 2nd trimester. There were positive associations with "number of work-family conflicts" for 2nd trimester but not for 3rd trimester. The others variables (occupational group, type of contract (fixed-term), company size, home-work commuting and, age) were positively associated with outcomes but only in the strate without PR.
Table 3 shows the RRa for "early SL" ( $<15$ WG) without returning to work until delivery (Table 2). The variables "number of occupational hazards", deprivation and "pregnancy at risk" were found to be associated with increased RRa of SL compared with the reference group. We always observed a gradient with "number of occupational hazards". Overall, $14.4 \%$ of pregnant workers left their job before 15 WG.

Table 4 displays the results for the ZINB model (Table 4). The logistic portion is based on the probability of zero days of SL. This probability decreased with the number of "occupational hazards for pregnancy", "workhome conflicts" or for "pregnancy at risk". Working in a small company or having a non-fixed term contract was also associated with no SL. For the negative binomial portion, the duration of SL was found to be clearly associated with "number of occupational hazards", "workfamily conflicts", deprivation and "pregnancy at risk". Here also the gradient with "number of occupational hazards" was reported.

\section{Discussion}

In our study, the rate of SL in pregnant workers was very high. After adjustment, the cumulative index of occupational hazards for pregnancy was clearly associated with SL (for "at least one leave", according to duration and for "early leave") in a dose-response relationship. We also found deprivation, pregnancy at risk, ART, work-family conflicts, home-work commuting felt as difficult, and young age to be associated with a higher risk of SL. For some factors, the results varied according to the trimesters of pregnancy. Moreover, we observed that there were less SL in small companies or for non-fixed term contract to 2 nd or 3rd trimester.

The study has a number of strengths and limitations. Among its strengths, it is noteworthy that exposure data and outcomes were collected independently of each other. The assessment of occupational exposures was carried out by OHPs with good knowledge of the workstations and the workers answered the questionnaire before visiting the OHPs. Also our results were improved by adjustment for socioeconomic deprivation based on the EPICES scale [12,31]. The other advantages of our study were its large size and the wide range of possible confounders collected, for which we adjusted our data. The large participation of OHPs in two French regions throughout the duration of the study and the high participation rate also improved the generalisability of our work. However, several potential limitations exist. High absence rates among pregnant workers may be caused by other characteristics not captured by the variables chosen in our study (e.g. job strain, other psychosocial factors) [19]. Information on outcomes was based on retrospectively collected self-reported information which 
Table 1 Characteristics of the pregnant workers according to the variable "at least one sick leave" (SL) during pregnancy

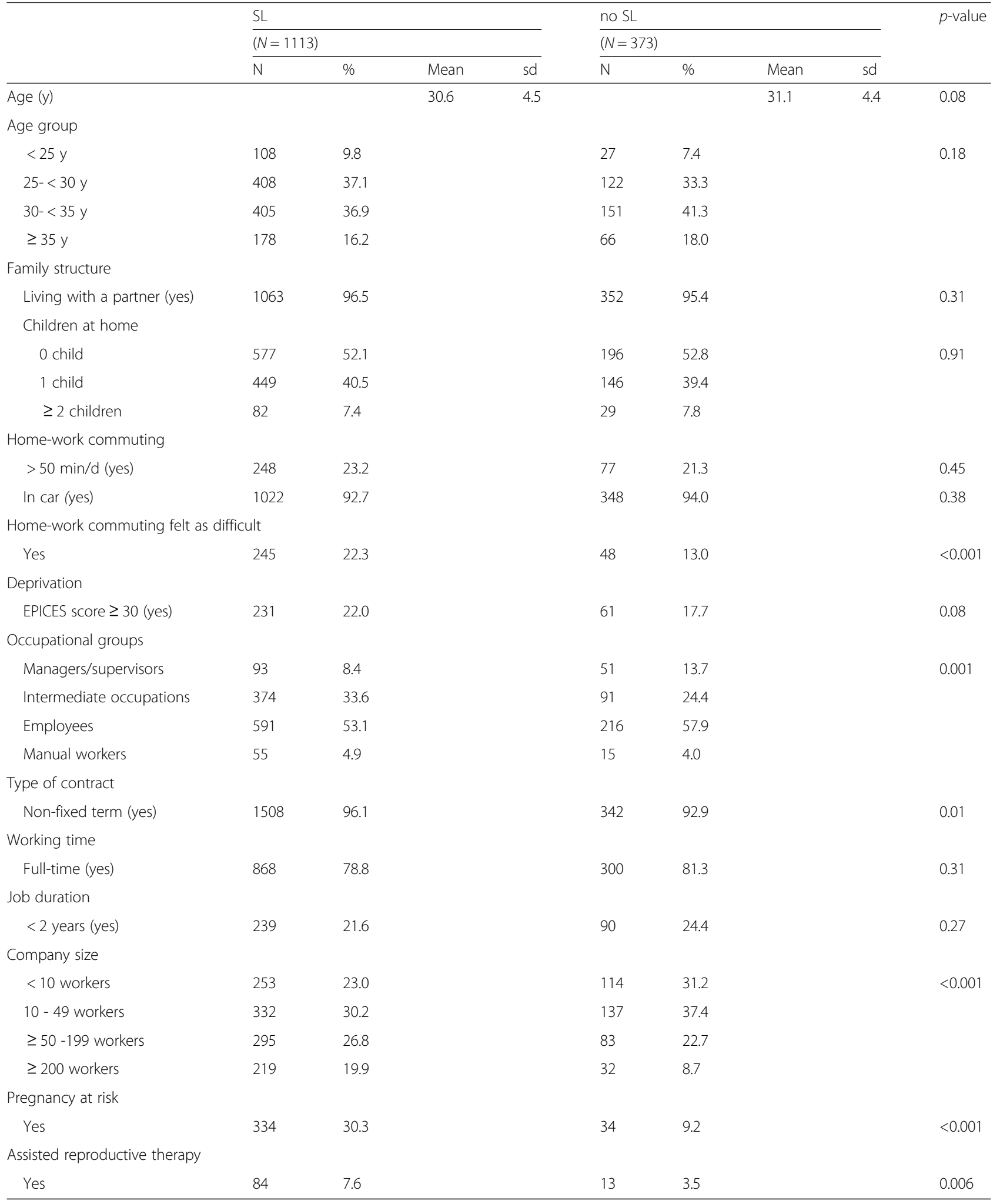

$N$ number, $y$ years, min minutes, $d$ day, sd standard deviation 


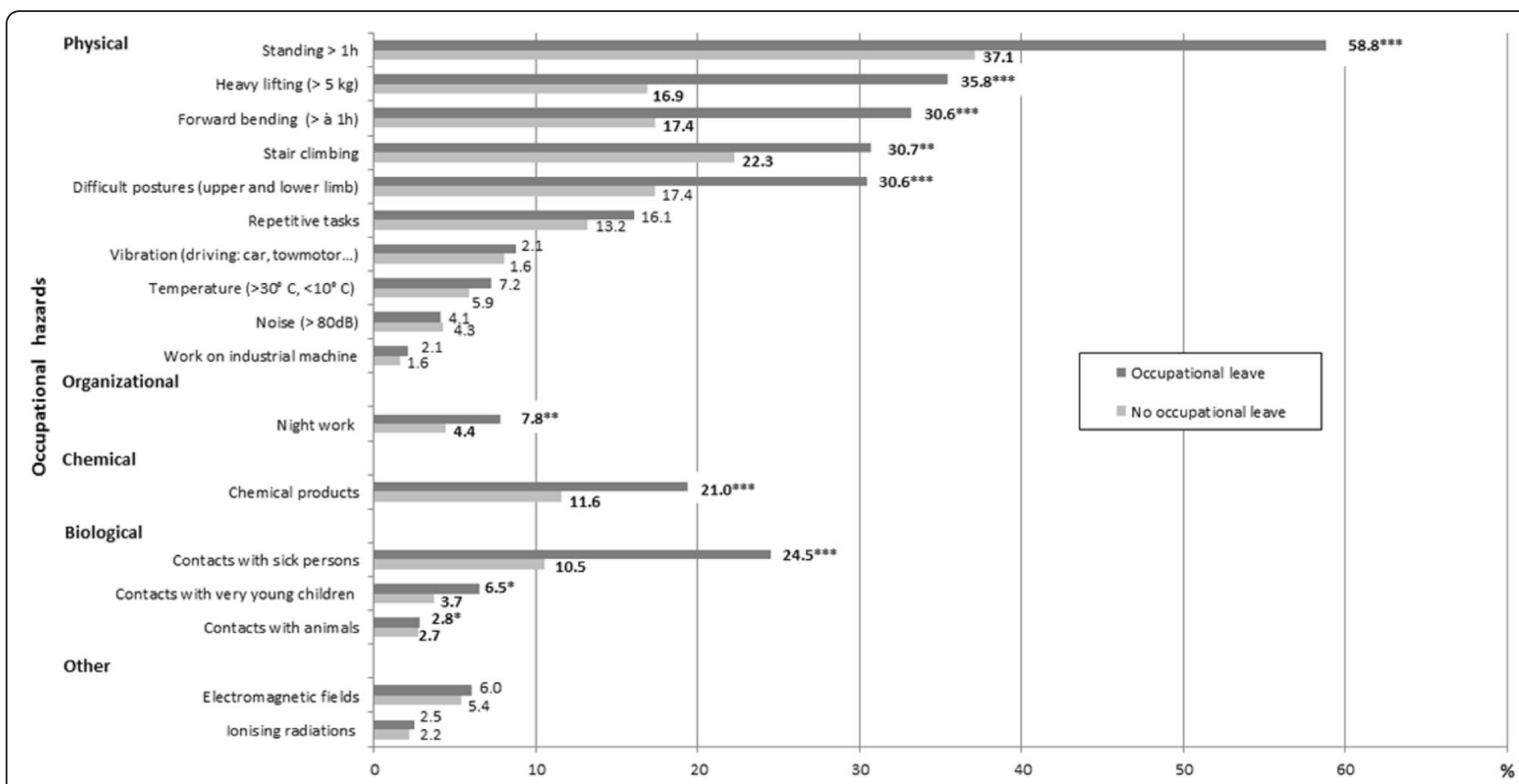

Fig. 2 Comparison of the frequencies of occupational hazards for pregnancy according to the occurrence of "at least one sick leave" ${ }^{*} p<0.05$, $\left.{ }^{* *} p<0.01,{ }^{* * *} p<0.001\right)$

may lead to errors with respect to both time of occurrence and duration. However, according to some studies, the duration from self-reported data tend to be shorter than those based on recorded data and agreement between self-reported and recorded days of absence decreased as the total number of days increased [32, 33]. Consequently, our results tend to rather underestimate reality. Also we did not have access to medical records relating to maternity and information on "pregnancy at risk" was based on self-reporting by workers. There was no consensual definition and literature data on this variable are scarce $[34,35]$. In a report from the French National Authority for Health, the rate of "pregnancy at risk" was $20 \%$ versus $24.8 \%$ for our study [34]. Our rate was probably overestimated since there was no medical control of the declarations from the workers.

The high rate of "at least one SL" (74.9\%) in our study is similar to that of a Norwegian study $(75.3 \%$, similar definition) [20] but higher than other studies from Norway (51\%) [24] and from Denmark (31\%) [7]. Our rate of "early leave" (14.4\% before $15 \mathrm{WG}$ ) was consistent with the results from other studies: $27.5 \%$ before 24 WG [15]; $43 \%$ before 28 WG [36]. With respect to the average number of days' absence without inclusion of the 15 days accepted for pathological leave, one study in French hospitals from 2005 to 2008 using data obtained from employers' records reported 33.6 days on average versus 31.9 to 53.8 days for our study (see Table 3) [9]. But it is difficult to compare the different studies globally because the populations studied and the definitions chosen are not similar $[4,19]$.
SL is expected when a pregnant woman is sick or medically at risk as this was confirmed by our results with the variables "pregnancy at risk" and ART, and reported by other studies [12, 15, 20]. However, our results adjusted for "pregnancy at risk" and ART argue strongly for the independent implication of occupational factors in the decision to take SL. Several studies have also reported that some working conditions were statistically related to SL: heavy lifting [7, 19, 37]; work with a lot of walking or standing [7]; uncomfortable working positions [7, 19]; night or shift work [7, 19, 24]; long working days [7]. Several studies have reported an association between the combination of occupational hazards and SL [9, 18, 37]. A French study in 1985 on hospital workers reported a longer duration of SL (including the supplementary week for pathological leave) was associated with the accumulation of occupational factors: 37 days on average for 0 to 1 risk; 50 days on average for 2 or 3 risks [18]. In another French study on hospital workers in 2008, the average number of days' absence after exclusion of women having had a pregnancy-related illness, increased with the physical load of the workstations [9].

Like other authors, we reported an association between early SL and socioeconomic deprivation in pregnant workers $[12,20]$. From literature data, early SL was more frequent among pregnant workers with unstable jobs and with less-qualified occupational categories [12]. Deprived pregnant workers were exposed to more occupational hazards for pregnancy and higher risk of pregnancy-related illnesses [12, 31]. In France, 
Table 2 Bernoulli generalized linear model with « at least one sick leave» (SL) as dependent variable according to 1st and 2nd trimester

\begin{tabular}{|c|c|c|c|c|c|c|c|c|c|c|c|c|c|c|c|}
\hline & \multirow{2}{*}{\multicolumn{3}{|c|}{$\begin{array}{l}\text { 1st trimester } \\
\text { with \& without PR } \\
(N=1257)\end{array}$}} & \multicolumn{6}{|c|}{ 2nd trimester } & \multicolumn{6}{|c|}{ 3rd trimester } \\
\hline & & & & \multicolumn{3}{|c|}{$\begin{array}{l}\text { strate without PR } \\
(N=939)^{\mathrm{a}}\end{array}$} & \multicolumn{3}{|c|}{$\begin{array}{l}\text { strate with PR } \\
(N=306)^{\mathrm{a}}\end{array}$} & \multicolumn{3}{|c|}{$\begin{array}{l}\text { strate without PR } \\
(N=939)^{\mathrm{a}}\end{array}$} & \multicolumn{3}{|c|}{$\begin{array}{l}\text { strate with PR } \\
(N=306)^{\mathrm{a}}\end{array}$} \\
\hline & $\overline{\operatorname{RRa}^{\mathrm{b}}}$ & $95 \% \mathrm{Cl}$ & $p$ & $\overline{\operatorname{RRa}^{c}}$ & $95 \% \mathrm{Cl}$ & $p$ & $\overline{\mathrm{RRa}^{\mathrm{d}}}$ & $95 \% \mathrm{Cl}$ & $p$ & $\overline{\mathrm{RRa}^{\mathrm{h}}}$ & $95 \% \mathrm{Cl}$ & $p$ & $\overline{\operatorname{RRa}^{i}}$ & $95 \% \mathrm{Cl}$ & $p$ \\
\hline \multicolumn{16}{|c|}{ Number of occupational risks ${ }^{e}$} \\
\hline No risk & Ref & & $<0.001$ & Ref & & $<0.001$ & Ref & & $<0.001$ & Ref & & $<0.001$ & Ref & & 0.25 \\
\hline 1 or 2 risks & 1.10 & $\begin{array}{l}0.78- \\
1.54\end{array}$ & & 1.96 & $\begin{array}{l}1.44- \\
2.66\end{array}$ & & 1.16 & $\begin{array}{l}0.89- \\
1.52\end{array}$ & & 1.32 & $\begin{array}{l}1.12- \\
1.54\end{array}$ & & 1.12 & $\begin{array}{l}0.95- \\
1.32\end{array}$ & \\
\hline 3 or 4 risks & 1.50 & $\begin{array}{l}1.06- \\
2.12\end{array}$ & & 2.05 & $\begin{array}{l}1.48- \\
2.86\end{array}$ & & 1.41 & $\begin{array}{l}1.09- \\
1.82\end{array}$ & & 1.55 & $\begin{array}{l}1.32 \text { - } \\
1.82\end{array}$ & & 1.15 & $\begin{array}{l}0.98- \\
1.35\end{array}$ & \\
\hline$\geq 5$ risks & 1.84 & $\begin{array}{l}1.40- \\
2.50\end{array}$ & & 2.46 & $\begin{array}{l}1.81- \\
3.34\end{array}$ & & 1.67 & $\begin{array}{l}1.34- \\
2.08\end{array}$ & & 1.57 & $\begin{array}{l}1.35- \\
1.83\end{array}$ & & 1.16 & $\begin{array}{l}1.00- \\
1.34\end{array}$ & \\
\hline \multicolumn{16}{|l|}{ Work-family conflict $^{\mathrm{f}}$} \\
\hline No risk & Ref & & 0.57 & Ref & & $<0.001$ & Ref & & 0.07 & Ref & & 0.36 & Ref & & 0.50 \\
\hline 1 risks & 0.93 & $\begin{array}{l}0.68- \\
1.27\end{array}$ & & 1.27 & $\begin{array}{l}0.98- \\
1.61\end{array}$ & & 1.13 & $\begin{array}{l}0.89- \\
1.44\end{array}$ & & 1.11 & $\begin{array}{l}0.97- \\
1.26\end{array}$ & & 1.07 & $\begin{array}{l}0.92- \\
1.24\end{array}$ & \\
\hline 2 risks & 1.00 & $\begin{array}{l}0.73- \\
1.38\end{array}$ & & 1.40 & $\begin{array}{l}1.07- \\
1.81\end{array}$ & & 1.29 & $\begin{array}{l}1.02- \\
1.64\end{array}$ & & 1.09 & $\begin{array}{l}0.95- \\
1.25\end{array}$ & & 1.09 & $\begin{array}{l}0.94- \\
1.27\end{array}$ & \\
\hline$\geq 3$ risks & 1.17 & $\begin{array}{l}0.81- \\
1.67\end{array}$ & & 1.69 & $\begin{array}{l}1.29- \\
2.22\end{array}$ & & 1.14 & $\begin{array}{l}0.87- \\
1.50\end{array}$ & & 1.03 & $\begin{array}{l}0.87- \\
1.22\end{array}$ & & 1.12 & $\begin{array}{l}0.96- \\
1.31\end{array}$ & \\
\hline \multicolumn{16}{|c|}{ Deprivation (EPICES score $\geq 30$ ) } \\
\hline No & Ref & & 0.02 & Ref & & 0.98 & Ref & & 0.17 & Ref & & 0.56 & Ref & & 0.64 \\
\hline Yes & 1.28 & $\begin{array}{l}1.04- \\
1.60\end{array}$ & & 1.00 & $\begin{array}{l}0.82- \\
1.22\end{array}$ & & 1.09 & $\begin{array}{l}0.96- \\
1.23\end{array}$ & & 0.97 & $\begin{array}{l}0.87- \\
1.08\end{array}$ & & 1.02 & $\begin{array}{l}0.93- \\
1.13\end{array}$ & \\
\hline \multicolumn{16}{|c|}{ Home-work commuting felt as difficult } \\
\hline No & Ref & & 0.27 & Ref & & 0.16 & Ref & & 0.78 & Ref & & $<0.001$ & Ref & & 0.63 \\
\hline Yes & 1.13 & $\begin{array}{l}0.99- \\
1.60\end{array}$ & & 1.13 & $\begin{array}{l}0.94- \\
1.35\end{array}$ & & 1.01 & $\begin{array}{l}0.89- \\
1.17\end{array}$ & & 1.25 & $\begin{array}{l}1.14- \\
1.37\end{array}$ & & 0.97 & $\begin{array}{l}0.87- \\
1.08\end{array}$ & \\
\hline \multicolumn{16}{|l|}{ Age group (years) } \\
\hline$<25$ & 1.01 & $\begin{array}{l}0.71- \\
1.43\end{array}$ & 0.65 & 1.52 & $\begin{array}{l}1.24- \\
1.85\end{array}$ & $<0.001$ & 1.00 & $\begin{array}{l}0.81- \\
1.25\end{array}$ & 0.55 & 1.34 & $\begin{array}{l}1.17- \\
1.54\end{array}$ & $<0.001$ & 0.89 & $\begin{array}{l}0.70- \\
1.13\end{array}$ & 0.30 \\
\hline $25-<30$ & 0.94 & $\begin{array}{l}0.74- \\
1.20\end{array}$ & & 1.04 & $\begin{array}{l}0.87- \\
1.24\end{array}$ & & 1.01 & $\begin{array}{l}0.87- \\
1.18\end{array}$ & & 1.14 & $\begin{array}{l}1.04- \\
1.26\end{array}$ & & 1.04 & $\begin{array}{l}0.93- \\
1.16\end{array}$ & \\
\hline $30-<35$ & Ref & & & Ref & & & Ref & & & Ref & & & Ref & & \\
\hline$\geq 35$ & 0.83 & $\begin{array}{l}0.61- \\
1.23\end{array}$ & & 0.97 & $\begin{array}{l}0.73- \\
1.28\end{array}$ & & 0.87 & $\begin{array}{l}0.71- \\
1.07\end{array}$ & & 1.02 & $\begin{array}{l}0.88- \\
1.17\end{array}$ & & 0.94 & $\begin{array}{l}0.82- \\
1.08\end{array}$ & \\
\hline \multicolumn{16}{|l|}{ Occupational group } \\
\hline $\begin{array}{l}\text { Managers/ } \\
\text { supervisors }\end{array}$ & Ref & & 0.34 & Ref & & 0.001 & Ref & & 0.33 & Ref & & 0.006 & Ref & & 0.97 \\
\hline $\begin{array}{l}\text { Intermediate } \\
\text { occupations }\end{array}$ & 1.11 & $\begin{array}{l}0.70- \\
1.74\end{array}$ & & 1.80 & $\begin{array}{l}1.19- \\
2.70\end{array}$ & & 1.36 & $\begin{array}{l}0.90- \\
1.96\end{array}$ & & 1.30 & $\begin{array}{l}1.04- \\
1.60\end{array}$ & & 1.00 & $\begin{array}{l}0.81- \\
1.25\end{array}$ & \\
\hline Employees & 1.16 & $\begin{array}{l}0.75- \\
1.79\end{array}$ & & 1.43 & $\begin{array}{l}0.96- \\
2.16^{9}\end{array}$ & & 1.31 & $\begin{array}{l}0.87- \\
1.96^{9}\end{array}$ & & 1.16 & $\begin{array}{l}0.93- \\
1.44^{9}\end{array}$ & & 1.02 & $\begin{array}{l}0.85- \\
1.22^{9}\end{array}$ & \\
\hline Manual workers & 1.54 & $\begin{array}{l}0.89- \\
2.65\end{array}$ & & & & & - & - & & & & & & & \\
\hline \multicolumn{16}{|c|}{ Company size (workers) } \\
\hline$<10$ & 0.76 & $\begin{array}{l}0.52- \\
1.13\end{array}$ & 0.55 & 0.85 & $\begin{array}{l}0.69- \\
1.06\end{array}$ & 0.38 & 0.88 & $\begin{array}{l}0.72- \\
1.08\end{array}$ & 0.55 & 0.79 & $\begin{array}{l}0.69- \\
0.90\end{array}$ & $<0.001$ & 0.89 & $\begin{array}{l}0.78- \\
1.02\end{array}$ & 0.40 \\
\hline $10-49$ & 0.82 & $\begin{array}{l}0.58 \text { - } \\
1.15\end{array}$ & & 0.84 & $\begin{array}{l}0.67 \text { - } \\
1.04\end{array}$ & & 0.95 & $\begin{array}{l}0.82- \\
1.11\end{array}$ & & 0.82 & $\begin{array}{l}0.74- \\
0.91\end{array}$ & & 0.95 & $\begin{array}{l}0.84- \\
1.07\end{array}$ & \\
\hline
\end{tabular}


Table 2 Bernoulli generalized linear model with « at least one sick leave» (SL) as dependent variable according to 1st and 2nd trimester (Continued)

\begin{tabular}{|c|c|c|c|c|c|c|c|c|c|c|c|c|c|c|c|}
\hline $50-199$ & 0.82 & $\begin{array}{l}0.58- \\
1.17\end{array}$ & & 0.86 & $\begin{array}{l}0.68- \\
1.09\end{array}$ & & 0.91 & $\begin{array}{l}0.77- \\
1.08\end{array}$ & & 0.87 & $\begin{array}{l}0.80- \\
0.96\end{array}$ & & 0.94 & $\begin{array}{l}0.82- \\
1.07\end{array}$ & \\
\hline$\geq 200$ & Ref & & & Ref & & & Ref & & & Ref & & & Ref & & \\
\hline \multicolumn{16}{|l|}{ Type of contract } \\
\hline Non-fixed term & Ref & & 0.20 & Ref & & 0.008 & Ref & & 0.56 & Ref & & 0.007 & Ref & & 0.57 \\
\hline Fixed-term & 1.51 & $\begin{array}{l}0.80- \\
2.85\end{array}$ & & 2.06 & $\begin{array}{l}1.21- \\
3.51\end{array}$ & & 1.10 & $\begin{array}{l}0.80- \\
1.50\end{array}$ & & 1.47 & $\begin{array}{l}1.11- \\
1.94\end{array}$ & & 1.10 & $\begin{array}{l}0.79- \\
1.51\end{array}$ & \\
\hline \multicolumn{16}{|l|}{ Pregnancy at risk } \\
\hline No & Ref & - & $<0.001$ & & & & & & & & & & & & \\
\hline Yes & 2.12 & $\begin{array}{l}1.72- \\
2.63\end{array}$ & & & & & & & & & & & & & \\
\hline \multicolumn{16}{|c|}{ Assisted reproductive therapy } \\
\hline No & Ref & - & 0.001 & & & & & & & & & & & & \\
\hline Yes & 1.54 & $\begin{array}{l}1.19- \\
2.00\end{array}$ & & & & & & & & & & & & & \\
\hline
\end{tabular}

$R R a$ ajusted relative risk, $95 \%$ Cl 95\% confidence intervals, $p$ p-value, $P R$ pregnancy at risk, Ref reference

${ }^{\text {a }}$ Positive interaction between variable pregnancy at risk and variable number of occupational risks at 2 nd trimester and at 3 rd trimester: presentation according to strate with pregnancy at risk and without pregnancy at risk

${ }^{\mathrm{b}}$ Ajusted for: number of occupational risks $(0,1$ or 2,3 or $4, \geq 5$ risks), deprivation EPICES score $\geq 30$ (yes/no), pregnancy at risk (yes/no), assisted reproductive therapy (yes/no)

${ }^{c}$ Ajusted for: number of occupational risks $(0,1$ or 2,3 or $4, \geq 5$ risks), number of home-work conflicts $(0,1,2,>2$ risks), age group ( $<25,25-<30,30-<35, \geq 35$ years), occupational group (managers/supervisors, intermediate occupations, employees + manual workers), type of contract (non-fixed term, fixed-term)

${ }^{\mathrm{d}}$ Ajusted for: number of occupational risks $(0,1$ or 2,3 or $4, \geq 5$ risks)

${ }^{\mathrm{e}}$ Among 17 selected occupational risks in this study

${ }^{f}$ Among preschool-age children at home (yes/no), home-work commuting $>50 \mathrm{~min} / \mathrm{d}$ (yes/no), duration of working hours $>8 \mathrm{~h} / \mathrm{d}$ (yes/no), irregular working hours (yes/no), and absent of two consecutive rest days in a week (yes/no)

${ }^{9}$ Grouping manual workers and employees because of small number of manual workers

hAjusted for: number of occupational risks ( 0,1 or 2,3 or $4, \geq 5$ risks), home-work commuting felt as difficult (yes/no), age group ( $<25,25-<30,30-<35, \geq 35$ years), occupational group (managers/supervisors, intermediate occupations, employees + manual workers), company size (<10, 10-49, 50-199, $\geq 200$ workers), type of contract (non-fixed term, fixed-term)

'Ajusted for: number of occupational risks $(0,1$ or 2,3 or $4, \geq 5$ risks), number of home-work conflicts $(0,1,2,>2$ risks)

Table 3 Bernoulli generalized linear model with "early sick leave" (SL) without returning to work until delivery ( $<15 \mathrm{WG})$ as dependent variable

\begin{tabular}{|c|c|c|c|}
\hline & \multicolumn{3}{|c|}{ Early sick leave $(N=1257)$} \\
\hline & $\overline{R R a^{\mathrm{a}}}$ & $95 \% \mathrm{Cl}$ & $p$ \\
\hline \multicolumn{4}{|c|}{ Number of occupational risks ${ }^{b}$} \\
\hline No risk & Ref & - & $<0.001$ \\
\hline 1 or 2 risks & 1.48 & $0.92-2.38$ & \\
\hline 3 or 4 risks & 2.03 & $1.25-3.30$ & \\
\hline$\geq 5$ risks & 2.90 & $1.89-4.44$ & \\
\hline \multicolumn{4}{|c|}{ Deprivation (EPICES score $\geq 30$ ) } \\
\hline No & Ref & - & 0.005 \\
\hline Yes & 1.45 & $1.12-1.88$ & \\
\hline \multicolumn{4}{|c|}{ Pregnancy at risk } \\
\hline No & Ref & & $<0.001$ \\
\hline Yes & 2.42 & $1.87-3.12$ & \\
\hline
\end{tabular}

$R R a$ risk, 95\% Cl 95\% confidence intervals, $p$ p-value, WG week gestation

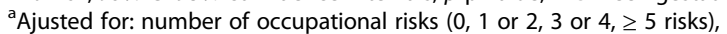
deprivation, EPICES score $\geq 30$ " (yes/no), pregnancy at risk (yes/no)

${ }^{\mathrm{b}}$ Among 17 selected occupational risks in this study pregnant workers can adapt their jobs using occupational health services, but not all women seem to benefit from those adjustments. Consequently, some deprived pregnant workers could leave early the workplace for those different reasons. In France in 2014 before legal or pathological leaves, except for some great companies, ordinary sick leaves were paid to $50 \%$ of the salary. From our study, pregnant workers with social vulnerabilities may decide to leave their job earlier than they legally can, even if they lose part of their income [12]. But this could have financial and social important consequences (isolation, less medical care). It is important to note that, in contrast with our result about early SL, sick leaves paid to $50 \%$ of the salary could also affect the use of sick leave among the poorest workers frequently exposed to occupational hazards during pregnancy (particularly of a physical nature) and could have some consequences on adverse perinatal outcomes [31]. One French study has reported that deprived pregnant workers exposed to three or more occupational hazards were significantly associated with preterm birth [31]. 
Table 4 Zero-inflated negative binomial model for number days of sick leave before pathological and legal maternity leaves

\begin{tabular}{|c|c|c|c|c|c|c|c|c|c|}
\hline & \multicolumn{4}{|c|}{ Logistic portion $^{a}$} & \multicolumn{5}{|c|}{ Negative binomial portion } \\
\hline & $\overline{\beta^{b}}$ & $95 \% \mathrm{Cl}$ & $p$ & $\begin{array}{l}\text { Probability of being } \\
\text { an extra zero }\end{array}$ & $\overline{\beta^{b}}$ & $95 \% \mathrm{Cl}$ & $p$ & $\begin{array}{l}\text { Adjusted mean } \\
\text { NOLD }^{c}\end{array}$ & $\begin{array}{l}\text { Difference } \\
\text { (factor-intercept) }^{c}\end{array}$ \\
\hline Intercept & 0.92 & $-0.08-1.91$ & 0.07 & 0.71 & 3.46 & $3.06-3.87$ & $<0.001$ & 31.9 & 0 \\
\hline \multicolumn{10}{|c|}{ Number of occupational risks } \\
\hline 1 or 2 risks vs 0 risk & -0.44 & $-0.83--0.06$ & $<0.001$ & 0.62 & 0.19 & $0.03-0.35$ & $<0.001$ & 38.6 & +06.7 \\
\hline 3 or 4 risks vs 0 risk & -0.74 & $-1.23--0.24$ & & 0.54 & 0.38 & $0.19-0.57$ & & 46.8 & +14.9 \\
\hline$\geq 5$ risks vs 0 risk & -1.05 & $-1.54--0.57$ & & 0.46 & 0.52 & $0.35-0.70$ & & 53.8 & +21.9 \\
\hline \multicolumn{10}{|l|}{ Work-family conflict } \\
\hline 1 risks vs 0 risk & 0.14 & $-0.23-0.52$ & 0.35 & 0.74 & 0.20 & $0.04-0.35$ & 0.03 & 38.8 & +6.9 \\
\hline 2 risks vs 0 risk & -0.14 & $-0.60-0.32$ & & 0.68 & 0.23 & $0.06-0.39$ & & 40.0 & +8.1 \\
\hline$\geq 3$ risks vs 0 risk & -0.33 & $-0.99-0.34$ & & 0.64 & 0.21 & $0.01-0.41$ & & 39.4 & +7.6 \\
\hline \multicolumn{10}{|c|}{ Deprivation (EPICES score $\geq 30$ ) } \\
\hline Yes vs no & -0.17 & $-0.59-0.25$ & 0.42 & 0.68 & 0.17 & $0.04-0.31$ & 0.01 & 37.9 & +6.0 \\
\hline \multicolumn{10}{|l|}{ Working time } \\
\hline Full-time vs part-time & 0.15 & $-0.24-0.53$ & 0.46 & 0.74 & -0.15 & $-0.29--0.01$ & 0.03 & 27.4 & -4.5 \\
\hline \multicolumn{10}{|c|}{ Home-work commuting felt as difficult } \\
\hline Yes vs no & & & $<0.001$ & 0.53 & 0.09 & $-0.04--0.22$ & 0.17 & 35.0 & +3.1 \\
\hline \multicolumn{10}{|l|}{ Pregnancy at risk } \\
\hline Yes vs no & -1.26 & $-1.72--0.80$ & $<0.001$ & 0.41 & 0.42 & $0.29-0.54$ & $<0.001$ & 48.3 & +16.5 \\
\hline \multicolumn{10}{|l|}{ Company size (workers) } \\
\hline$\geq 50-199$ vs $\geq 200$ & 0.64 & $0.09-1.18$ & 0.02 & 0.68 & 0.07 & $-0.12-0.25$ & 0.34 & 34.0 & +2.1 \\
\hline $10-49 v s \geq 200$ & 0.69 & $0.17-1.20$ & & 0.83 & 0.02 & $-0.14-0.19$ & & 32.7 & +0.8 \\
\hline$<10 v s \geq 200$ & 0.29 & $-0.25-0.82$ & & 0.77 & -0.08 & $-0.24-0.09$ & & 29.4 & -2.4 \\
\hline \multicolumn{10}{|l|}{ Type of contract } \\
\hline $\begin{array}{l}\text { Fixed-term } \\
\text { vs non-fixed term }\end{array}$ & -1.03 & $-1,71--0.35$ & 0.003 & 0.47 & 0.26 & $-0.06-0.58$ & 0.11 & 41.2 & +9.4 \\
\hline
\end{tabular}

RRa ajusted relative risk, $95 \% \mathrm{Cl}$ 95\% confidence intervals, $p$ p-value, NOLD number of sick leave days vs: versus

${ }^{a}$ Modeling the probability of being an extra zero

${ }^{b}$ Ajusted for: number of occupational risks $(0,1$ or 2,3 or $4, \geq 5$ risks), number of home-work conflicts $(0,1,2, \geq 3$ risks), deprivation EPICES score $\geq 30$ (yes/no), pregnancy at risk (yes/no), working time (full-time, part-time), company size $(<10,10-49, \geq 50-199, \geq 200$ workers), type of contract (non-fixed term, fixed term), home-work commuting felt as difficult (yes/no)

cin days

We observed an association between "at least one SL" and "number of home-work conflicts" or "home-work commuting felt as difficult". Fatigue, pain or discomfort during pregnancy are expected to be more frequent in the last trimesters than in the 1st trimester and could explain these specific associations. However, some women also still have the double burden of combining their household and child-rearing responsibilities with their jobs [11]. Pregnant workers may need to leave their job when this double burden can no longer be ensured [11]. Furthermore, we found an association between "at least one SL" and younger women ( $<25$ years), as in certain other studies $[8,11,16]$, but not others with different cut-offs $[7,19]$. First pregnancy and inexperience related to age or specific representation such as "absence from work is considered beneficial for the child" may explain this result [11]. In our study, the relationship between occupational classes and SL after adjustment is not clear. This may be explained by a lower SL rate in the reference group rather than higher rates in other groups; underreporting of SL cannot be ruled out, because in general managers/supervisors are averse to declaring SL. In contrast, the observations of less SL in small companies or for non-fixed term contract are expected results because the risk losing his job (during or after pregnancy) is more important in these situations.

Our study has some practical perspectives. French labor law provides for a visit with an OHP after delivery but not before [3]. Consequently, few pregnant workers see an OHP during pregnancy. However, the situation for an OHP who receives pregnant workers may be difficult if they cannot propose job adjustments or other preventive measures in the workplace. Indeed, sometimes job adjustment is not possible because some employers 
may prefer pregnant workers to take sick leave so they can employ a healthy person to replace them during their absence [37]. Moreover, social conditions and, specific attitudes (for example, related to health beliefs) among pregnant workers may explain some SLs [16]. Also, some prenatal caregivers who care for pregnant workers without real knowledge of the workstation and without contact with OHPs may opt to prescribe SL to prevent disorders associated with pregnancy [21, 22]. At present, the management of employment during pregnancy results from complex interplay between the worker, employer, prenatal caregiver and, other influences $[21,22]$. In addition, some pregnant workers are likely excluded from work without having had an assessment of possible preventive measures in the workplace $[2,31]$. When occupational hazards for pregnancy exist, our results argue for a risk assessment in the workplace during early pregnancy, preferably with an OHP [3]. The aim would be to avoid reproductive risks by removing hazards or adjusting work [2, 3, 23].

\section{Conclusion}

Our results argue for the implication of exposure of the occupational hazards for pregnancy as an explanation for the occurrence of SL. More prevention in the workplace for pregnant workers exposed to occupational hazards could reduce SL. Further studies are needed to demonstrate that reducing SL might not be associated with a higher number of pregnancy-related illnesses and convince all the stakeholders (workers, employers, caregivers) to go in this direction. Our results also suggest that the duration and occurrence of early SL are significant in deprived pregnant workers. In addition, future studies should also take into account this vulnerable population in their analyses.

\section{Abbreviations \\ ART: Assisted reproductive therapy; OHPs: Occupational health physicians; RRa: Adjusted relative risks; SL: Sick leave; WG: Week of gestation; ZINB: \\ Zero-inflated negative binomial}

\section{Acknowledgments}

The authors would like to acknowledge the effort of the occupational health physicians who collected the data through the medical visits.

\section{Funding}

Not applicable.

\section{Availability of data and materials}

Please contact author for data request.

\section{Author's contribution}

$J B H, M V, M E$ and $D L$ edited the protocol. JBH, MV, ME, DL and MD built the questionnaire. MV and ME coordinated the collection of data. MD managed global data. JBH and MD analysed data. JBH, MV, ME, SM and DL drafted the manuscript. All authors read and approved the final manuscript.

\section{Competing interests}

The authors declare that they have no competing interests.

\section{Consent for publication}

Not applicable.

\section{Ethics approval and consent to participate}

All the volunteer participants gave their informed consent to be enrolled and data were collected anonymously. Ethics approval, not applicable.

\section{Publisher's Note}

Springer Nature remains neutral with regard to jurisdictional claims in published maps and institutional affiliations.

\section{Author details}

'Department of Occupational Epidemiology, National Research and Safety Institute, 1 rue du Morvan, CS 60027, Vandoeuvre-les-Nancy 54519 Cedex, France. ${ }^{2}$ Occupational Health Service, Santé Travail Béziers Coeur d'Hérault, Béziers, France. ${ }^{3}$ Occupational Health Service, Santé Travail Loire Nord, Roanne, France. ${ }^{4}$ Department of Medical Studies and Assistance, National Research and Safety Institute, Paris, France.

${ }^{5}$ Occupational Disease Consultation Centre, Raymond Poincaré Hospital, Garches, France.

Received: 6 January 2017 Accepted: 10 May 2017

Published online: 15 May 2017

\section{References}

1. Salihu HM, Myers J, August EM. Pregnancy in the workplace. Occup Med (Lond). 2012;62(2):88-97.

2. Paul J. Healthy beginnings: guidance on safe maternity at work. Geneva: International Labour Office; 2004.

3. Servan-Schreiber E, Lafon D, Puech F, Deruelle P. Knowing the main occupational risks for pregnant women. Rev Prat. 2014;64(2):247-56.

4. Alexanderson K, Hensing G, Carstensen J, Bjurulf P. Pregnancy-related sickness absence among employed women in a Swedish county. Scand J Work Environ Health. 1995;21(3):191-8.

5. Sydsjö A, Sydsjö G, Alexanderson K. Influence of pregnancy-related diagnoses on sick-leave data in women aged 16-44. J Womens Health Gend Based Med. 2001;10(7):707-14.

6. Sydsjö G, Sydsjö A. Newly delivered women's evaluation of personal health status and attitudes towards sickness absence and social benefits. Acta Obstet Gynecol Scand. 2002;81(2):104-11.

7. Kaerlev L, Jacobsen LB, Olsen J, Bonde JP. Long-term sick leave and its risk factors during pregnancy among Danish hospital employees. Scand J Public Health. 2004;32(2):111-7.

8. Ariansen AMS. Age, occupational class and sickness absence during pregnancy: a retrospective analysis study of the Norwegian population registry. BMJ Open. 2014;4(5):e004381.

9. Estryn-Behar M, Amar E, Choudat D. Sick leave during pregnancy: an analysis of French hospitals from 2005 until 2008 demonstrates the major importance for jobs with physical demands. Rech Soins Infirm. 2013;113:51-60.

10. Melsom AM. Long-term sickness absence during pregnancy and the gender balance of workplaces. Scand J Public Health. 2014;42(7):627-34.

11. Rieck KME, Telle K. Sick leave before, during and after pregnancy. Acta Soc. 2013;56(2):117-37.

12. Vigoureux S, Blondel B, Ringa V, Saurel-Cubizolles MJ. Occupational, social and medical characteristics of early prenatal leave in France. Eur J Public Health. 2016;26(6):1022-7.

13. Kalboussi H, Bannour D, Kacem I, Debbabi F, Haj Salah H, Mrizak N. Influence of occupational factors on pregnant women's absenteeism in central Tunisia. Arch Mal Prof Enviro. 2015;76:468-77.

14. Sydsjö A, Claesson IM, Ekholm Selling K, Josefsson A, Brynhildsen J, Sydsjö $\mathrm{G}$. Influence of obesity on the use of sickness absence and social benefits among pregnant working women. Public Health. 2007;121(9):656-62.

15. Hansen ML, Thulstrup AM, Juhl M, Kristensen JK, Ramlau-Hansen CH. Predictors of sickness absence in pregnancy: a Danish cohort. Scand J Work Environ Health. 2015;41(2):184-93.

16. Sydsjö A, Sydsjö G, Kjessler B. Sick leave and social benefits during pregnancy-a Swedish-Norwegian comparison. Acta Obstet Gynecol Scand. 1997;76(8):748-54.

17. Sydsjö G, Sydsjö A, Wijma B. Variations in sickness absence and use of social benefits among pregnant women in a Swedish community 1978-1997. Acta Obstet Gynecol Scand. 1999;78(5):383-7. 
18. Saurel-Cubizolles MJ, Kaminski M, Llado-Arkhipoff J, Du Mazaubrun C, Estryn-Behar M, Berthier C, et al. Pregnancy and its outcome among hospital personnel according to occupation and working conditions. J Epidemiol Community Health. 1985:39(2):129-34.

19. Hansen ML, Thulstrup AM, Juhl M, Kristensen JK, Ramlau-Hansen CH. Occupational exposures and sick leave during pregnancy: results from a Danish cohort study. Scand J Work Environ Health. 2015;41(4):397-406.

20. Dørheim SK, Bjordatn B, Eberhard-Gran M. Sick leave during pregnancy: a longitudinal study of rates and risk factors in a Norwegian population. BJOG. 2013;120(5):521-30.

21. Gustavsson C, Kjeldgård L, Bränström R, Lindholm C, Ljungquist T, Nilsson $\mathrm{GH}$, et al. Problems experienced by gynecologists/obstetricians in sickness certification consultations. Acta Obstet Gynecol Scand. 2013:92(9):1007-16.

22. Larsson C, Sydsjo A, Alexanderson K, Sydjo G. Obstetricians' attitudes and opinions on sickness absence and benefits during pregnancy. Acta Obstet Gynecol. 2006;85(2):165-70.

23. Strand K, Wergeland E, Bjerkedal T. Job adjustment as a means to reduce sickness absence during pregnancy. Scand J Work Environ Health. 1997; 23(5):378-84.

24. Kristensen P, Nordhagen R, Wergeland E, Bjerkedal T. Job adjustment and absence from work in mid-pregnancy in the Norwegian Mother and Child Cohort Study (MoBa). Occup Environ Med. 2008;65(8):560-6.

25. Labbe E, Blanquet M, Gerbaud L, Poirier G, Sass C, Vendittelli F, et al. A new reliable index to measure individual deprivation: the EPICES score. Eur J Public Health. 2015;25(4):604-9.

26. Institut National de la statistique et des Etudes Economiques. Nomenclature des professions et catégories socio-professionnelles (PCS). http://www.insee.fr/ fr/methodes/default.asp?page=nomenclature/pcs.htlm. Accessed 17 Feb 2016.

27. Jansen NW, Kant IJ, van Amelsvoort LG, Kristensen TS, Swaen GM, Nijhuis FJ. Work-family conflict as a risk for sickness absence. Occup Med Med. 2006; 63:488-94.

28. Kengatharan $\mathrm{N}$. The nature of work family conflict: A review and agenda for future research. Int J Human Resour Stud. 2015;5(2):163-88.

29. McCullagh P, Nelder JA. Generalized linear models. 2nd ed. London: Chapman \& Hall/CRC; 1989.

30. Hilbe JM. Modeling count data. 1st ed. Cambridge: University Press; 2014.

31. Henrotin JB, Vaissière M, Etaix M, Dziurla M, Radauceanu A, Malard S, et al. Deprivation, occupational hazards and perinatal outcomes in pregnant workers. Occup Med (Lond). 2017:67(1):44-51.

32. Voss M, Stark S, Alfredsson L, Vingard E, Josephson M. Comparisons of selfreported and register data on sickness absence among public employees in Sweden. Occup Environ Med. 2008;65(1):61-7.

33. Ferrie JE, Kivimäki M, Head J, Shipley MJ, Vahtera J, Marmot MG. A comparison of self-reported sickness absence with absences recorded in employers' registers: evidence from the Whitehall II study. Occup Environ Med. 2005;62(2):74-9.

34. French National Authority for Health. Pregnancies at risk: guidance pregnant women between maternity centers for delivery. 2009. Accessed 2 Sept 2016. www.has-sante.fr/portail/upload/docs/application/pdf/2010-04/ grossesses a risque _ _argumentaire.pdf.

35. Selvi Dogan F, Calmelet F, Cottenet J, Sagot F, Mace G. Does low-risk delivery exists? J Gynecol Obstet Biol Reprod (Paris). 2013;42(6):557-63.

36. Blondel B, Lelong N, Kermarrec M, Goffinet F. National Coordination Group of the National Perinatal Surveys. Trends in perinatal health in France from 1995 to 2010. Results from the French National Perinatal Surveys. J Gynecol Obstet Biol Reprod (Paris). 2012;41(4):e1-e15.

37. Saurel-Cubizolles MJ, Kaminski M. Pregnant women's working conditions and their changes during pregnancy: a national study in France. Br J Ind Med. 1987;44(4):236-43.

\section{Submit your next manuscript to BioMed Central and we will help you at every step:}

- We accept pre-submission inquiries

- Our selector tool helps you to find the most relevant journal

- We provide round the clock customer support

- Convenient online submission

- Thorough peer review

- Inclusion in PubMed and all major indexing services

- Maximum visibility for your research

Submit your manuscript at www.biomedcentral.com/submit

) Biomed Central 